\title{
Postoperative atrial arrhythmias: Where do we go from here?
}

\author{
Felix G. Fernandez, MD, MSc
}

\footnotetext{
From the Division of Cardiothoracic Surgery, Department of Surgery, Emory University School of Medicine, Atlanta, Ga.

Disclosures: Authors have nothing to disclose with regard to commercial support.

Received for publication Nov 30, 2015; accepted for publication Dec 1, 2015; available ahead of print Jan 15, 2016.

Address for reprints: Felix G. Fernandez, MD, MSc, Division of Cardiothoracic Surgery, Department of Surgery, Emory University School of Medicine, 1365 Clifton Rd, NE, Suite A2214, Atlanta, GA 30322 (E-mail: felix. fernandez@emoryhealthcare.org).

J Thorac Cardiovasc Surg 2016;151:990-1

$0022-5223 / \$ 36.00$

Copyright (c) 2016 by The American Association for Thoracic Surgery

http://dx.doi.org/10.1016/j.jtcvs.2015.12.012
}

The development of a postoperative supraventricular tachycardia (POSVT) after pulmonary resection has been well documented, and its consequences have been analyzed extensively. POSVT has been associated with adverse outcomes, including mortality, increased length of stay, hospital readmission, and costs. In addition, many factors associated with POSVT have been identified, such as age, gender, race, operative approach, and medical comorbidities. In this edition of the Journal, Dr Giambrone and colleagues ${ }^{1}$ examine the incidence of and adverse outcomes associated with POSVT after pulmonary lobectomy in a large administrative dataset, the State Inpatient Databases of New York, Florida, and California from the Healthcare Cost and Utilization Project. ${ }^{1}$ This work is reassuring in that risk factors for POSVT established in clinical registries, such as the Society of Thoracic Surgeons (STS) General Thoracic Surgery Database, are confirmed in a large dataset maintained for administrative purposes. Also confirmed is that POSVT is associated with worse outcomes for the patient and places added burden on the healthcare system. What is concerning is that despite a body of literature on POSVT after pulmonary resection, the incidence of this complication has not appreciably changed over time. The authors should be congratulated for bringing this issue back to the attention of the thoracic surgical community.

Both the American Association for Thoracic Surgery and the STS have recognized the importance of POSVT and have set forth guidelines for the prevention and management of atrial arrhythmias after pulmonary resection., These guidelines recommend postoperative rhythm monitoring after lobectomy and consideration of pharmacologic prophylaxis. The American Association for Thoracic Surgery and STS guidelines give a class IIa recommendation stating that it is reasonable to consider preoperative diltiazem (in patients not taking betablockers) or postoperative amiodarone to patients at moderate to high risk of POSVT, with a level of evidence of $\mathrm{B}$. These guidelines consider pulmonary resections as a

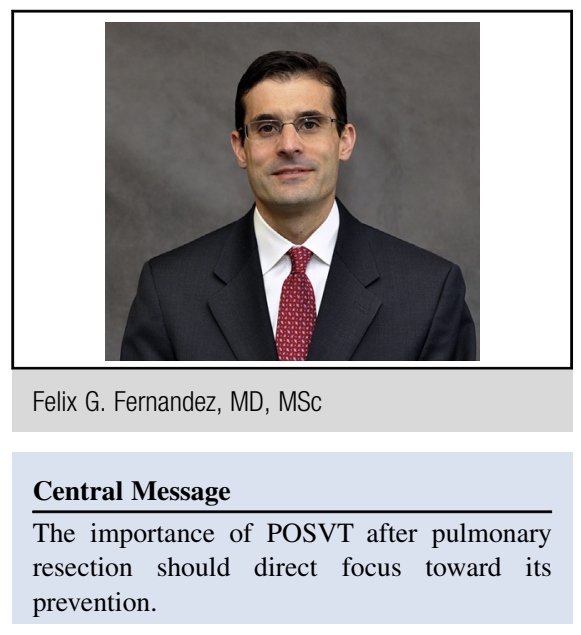

See Article page 982.

See Editorial page 913.

whole, although gradations in risk based on specific patient risk factors have been demonstrated in several studies, such as the current analysis by Dr Giambrone and colleagues. ${ }^{1}$ Clearly, a knowledge gap still exists regarding the optimal prevention of this condition.

Our healthcare systems are focused on moving toward alternative payment methods in which an emphasis is placed on paying for value rather than quantity of services rendered. Reduction of risk-adjusted rates of POSVT after pulmonary resection would be a marker of quality care. Unfortunately, although administrative databases can identify factors associated with POSVT, they lack the clinical detail necessary for the development of a predictive nomogram that may identify patient cohorts at high risk for POSVT after pulmonary resection. Clinical registries, such as the STS General Thoracic Surgery Database, are ideally suited to assess risk, guide implementation of quality improvement initiatives, and measure the effectiveness of these interventions. Development of a risk model for POSVT in a robust clinical registry could aid the development of an appropriately powered trial targeted at the highest risk group of patients. Such a paradigm could improve patient outcomes and at the same time greatly increase the value of the databases in which our specialty has so richly invested. Further studies identifying POSVT as an important morbidity after pulmonary resection are not needed. The time has come to use the data we have acquired to implement an intervention and study it with scientific rigor to improve 
outcomes for our patients and the value of the services we deliver.

\section{References}

1. Giambrone GP, Wu X, Gaber-Baylis LK, Bhat AU, Zabih R, Altorki NK, Fleischut PM, Stiles BM. Incidence and implications of postoperative supraventricular tachycardia following pulmonary lobectomy. J Thorac Cardiovasc Surg. 2016;151:982-9.
2. Frendl G, Sodickson AC, Chung MK, Waldo AL, Gersh BJ, Tisdale JE, et al. 2014 AATS guidelines for the prevention and management of perioperative atrial fibrillation and flutter for thoracic surgical procedures. J Thorac Cardiovasc Surg. 2014;148:e153-93.

3. Fernando HC, Jaklitsch MT, Walsh GL, Tisdale JE, Bridges CD, Mitchell JD, et al. The Society of Thoracic Surgeons practice guideline on the prophylaxis and management of atrial fibrillation associated with general thoracic surgery: executive summary. Ann Thorac Surg. 2011;92: 1144-52. 